\title{
AGROMETEOROLOGIA
}

\section{MODELO AGROMETEOROLÓGICO DE ESTIMATIVA DO INÍCIO DA FLORADA PLENA DO CAFEEIRO ( $\left.{ }^{1}\right)$}

\author{
ALINE OLIVEIRA ZACHARIAS $\left({ }^{2}\right)$; MARCELO BENTO PAES DE CAMARGO $\left({ }^{3 * 5}\right)$; \\ LUIZ CARLOS FAZUOLI $\left({ }^{4,5}\right)$
}

\begin{abstract}
RESUMO
Observações efetuadas em cafeeiros adultos, em diferentes condições tropicais do Brasil, revelam que as gemas florais completam a maturação e entram em dormência, ficando prontas para a antese, quando o somatório da evapotranspiração potencial (ETp), a partir de abril, atinge cerca de $350 \mathrm{~mm}$. O objetivo deste trabalho foi parametrizar e validar um modelo agrometeorológico de estimativa do início da fase da floração plena do cafeeiro arábica para as condições do Estado de São Paulo. Anotações fenológicas do café arábica, cultivares Mundo Novo e Catuaí, em fase adulta, foram obtidas de arquivos do Instituto Agronômico (IAC), referentes a duas regiões do Estado, Campinas e Mococa, no período de 1993 a 2005. Como indicador do fator térmico, relacionado com a fenologia do cafeeiro, considerou-se inicialmente o valor sugerido de $350 \mathrm{~mm}$ relativo ao somatório decendial de ETp, a partir de abril, e a quantidade mínima de chuva de $10 \mathrm{~mm}$ no decêndio, necessária para que as gemas maduras sejam induzidas à antese conforme o modelo original. Consideraram-se, também, outros valores de ETp e de graus-dia (GD) e também de chuva mínima (1 a 10mm). O modelo agrometeorológico parametrizado, que considera os valores acumulados de ETp $(335 \mathrm{~mm})$ ou de GD (1579) para as gemas florais atingirem a maturação e um mínimo de $7 \mathrm{~mm}$ de chuva para quebrar a dormência das gemas maduras, apresentou melhor capacidade de indicar a época da plena floração do cafeeiro arábica, com erros de estimativa inferiores ao do modelo original.
\end{abstract}

Palavras-chave: Coffea arabica L., clima, fenologia, maturação das gemas, florescimento.

$\left({ }^{1}\right)$ Projeto financiado pelo Consórcio Brasileiro de Pesquisa e Desenvolvimento do Café (EMBRAPA/PNP\&D/CAFÉ). Recebido para publicação em $1 .^{\circ}$ de fevereiro de 2007 e aceito em 30 de julho de 2007.

$\left({ }^{2}\right)$ Aluna de Mestrado no Curso de Agricultura Tropical e Subtropical, área de Concentração Tecnologia da Produção Agrícola, IAC/APTA, Caixa Postal 28, 13001-970 Campinas (SP). Com bolsa CAPES. E-mail: ninazac@yahoo.com.br.

$\left({ }^{3}\right)$ Centro de Pesquisa e Desenvolvimento de Ecofisiologia e Biofísica, Instituto Agronômico, Campinas (SP). E-mail: mcamargo@iac.sp.gov.br. $\left(^{*}\right)$ Autor correspondente.

$\left({ }^{4}\right)$ Centro de Análise e Pesquisa do Agronegócio do Café “Alcides Carvalho", Instituto Agronômico, Campinas (SP). E-mail: fazuoli@iac.sp.gov.br.

$\left({ }^{5}\right)$ Com bolsa de produtividade científica CNPq. 


\title{
ABSTRACT \\ AGROMETEOROLOGICAL MODEL FOR ESTIMATING THE BEGINNING OF THE FLOWERING PERIOD FOR COFFEE CROP (Coffea arabica L.)
}

\begin{abstract}
Phenological observations made in adult coffee crops, under tropical conditions of Brazil, indicated that flowering buds complete the maturation and reach to the dormancy of the buds, being ready for the main flowering when the accumulated value of potential evapotranspiration (ETp), starting from April, reaches about $350 \mathrm{~mm}$ and a minimum amount of rainfall of $10 \mathrm{~mm}$ is necessary so that the mature buds are induced to antesis, such as the original model. The objective was the parametrization and validation of the agrometeorological model for estimating the beginning of the full flowering period for arabic coffee for the conditions of the State of São Paulo. Phenological observations of adult coffee crops, variety Mundo Novo and Catuaí, were obtained from arhieves of the Instituto Agronomico (IAC), in Campinas, for two tropical areas, Campinas and Mococa, during the years of 1993 to 2005. Different accumulated values of ETp and Growing Degree Days (GDD) and values of minimum rainfall (1 to $10 \mathrm{~mm}$ ) also were considered. The parametrized agrometeorological model, that considers the accumulated values of ETp (335 mm) or GDD (1579), for the flower buds to reach the maturation, and a minimum value of $7 \mathrm{~mm}$ of rainfall presented better capacity to indicate the period of the full flowering for arabic coffee plants, with minors errors of estimating comparing to the original model.
\end{abstract}

Key words: Coffea arabica L., climate, phenology, floral buds maturation, flowering.

\section{INTRODUÇÃO}

A estimativa antecipada da produção de café é de fundamental importância para o estabelecimento da política cafeeira no país e ao adequado planejamento da cultura. A adoção de sistemas confiáveis de previsão de safra pela maioria dos países produtores é um instrumento importante para diminuir a volatilidade do mercado.

Contudo, ainda não existe um método adequado para a previsão antecipada da safra de café no Brasil, que permita uma avaliação mais segura e precisa. Esse fato se deve à complexidade ocasionada pela diversidade dos fatores ambientais, culturais e econômicos envolvidos na produtividade desta cultura.

Modelos matemáticos agrometeorológicos que relacionam condições ambientes, como temperatura e disponibilidade hídrica no solo, com fenologia, bienalidade e produtividade do cafeeiro estão sendo desenvolvidos para as regiões cafeeiras do Brasil. Esses modelos consideram que cada variável meteorológica exerce controle na produtividade da cultura por influenciar em determinados períodos fenológicos críticos, como na indução floral, na floração, na formação e na maturação dos frutos dos cafeeiros (CAMARGo et al., 2003; CARVALHO et al., 2003; Silva et al., 2005).

O modelo agrometeorológico, proposto por CAmargo e CAmargo (2001), que considera o somatório da evapotranspiração potencial (ETp), a partir de abril, igual a $350 \mathrm{~mm}$ para que as gemas florais completem a maturação e entrem em dormência, em conjunto com a ocorrência de no mínimo $10 \mathrm{~mm}$ de chuva no decêndio, necessária para induzir à antese, revela razoável capacidade de indicar o início do período da florada principal do café arábica, apresentando erros de estimativa inferiores a um decêndio.

A ETp é um elemento climatológico fundamental proposto por THORNTHWAITE (1948) para indicar a disponibilidade de energia solar na região, constituindo, assim, um índice de eficiência térmica da região, semelhante aos graus-dia (GD), porém sendo expresso em milímetros ( $\mathrm{mm}$ ) de evaporação equivalente. A ETp acumulada é muito utilizada na definição das disponibilidades térmicas, como nos trabalhos de zoneamento climático da aptidão agrícola e definição de fases fenológicas. Enquanto os valores da temperatura do ar e de graus-dia são expressos em graus, simples índices termométricos, a ETp é dada em milímetros de evaporação, equivalente a uma unidade física quantitativa (CAMARGO e CAMARGO, 2000). O conceito de graus-dia (ARNOLD, 1959), baseiase no fato de que a taxa de desenvolvimento de uma espécie vegetal está relacionada à temperatura do meio. Para isso, pressupõe a existência de temperatura basal inferior, abaixo da qual a planta não se desenvolve.

Santos e Camargo (2006) modificaram, parametrizaram e testaram o modelo matemático agrometeorológico de monitoramento que visa estimar a quebra relativa de produtividade esperada do café desenvolvido por CAMARGO et al. (2003), para três níveis hierárquicos (planta, talhão e propriedade rural), alterando somente o coeficiente de penalização pelo fator bienalidade; tal modelo multiplicativo é composto por 
componentes fenológicos, hídricos e térmicos. Conforme os testes as produtividades estimadas pelo modelo, nos três níveis hierárquicos, possuem bom grau de exatidão, mas com tendência a superestimar levemente as produtividades. Pelo modelo matemático modificado e parametrizado, que considera penalizações por déficit hídrico, adversidades térmicas e bienalidade, mostrou bom desempenho nas estimativas de quebra de produtividade do cafeeiro.

Entretanto, para ser incorporado em modelos de monitoramento e de estimativa de quebra de produtividade, que necessitam desta informação fenológica, são necessários mais estudos para determinar com maior precisão os limites térmicos e hídricos para a maturação das gemas florais e a quebra da dormência para a antese (SAntos e CAMARGO, 2006).

Portanto, foi desenvolvido este trabalho com o objetivo de identificar os elementos e fatores climáticos que interferem nos diferentes subperíodos fenológicos do cafeeiro, com ênfase na fase da floração; desenvolver, parametrizar e validar modelo agrometeorológico de estimativa do início da fase da floração plena do cafeeiro arábica para as condições tropicais do Estado de São Paulo.

\section{MATERIAL E MÉTODOS}

\subsection{Dados fenológicos de café}

Dados fenológicos de café Coffea arabica (L.) cv. Mundo Novo e cv. Catuaí, em fase adulta, foram obtidos em nível de talhão, junto aos arquivos dos Centros de Análise e Pesquisa Tecnológica do Agronegócio do Café "Alcides Carvalho" e de Pesquisa e Desenvolvimento em Ecofisologia e Biofísica do IAC, de experimentos e observações realizados durante treze anos (1993 a 2005), em duas regiões agroecológicas do Estado de São Paulo, referentes aos municípios de Mococa e Campinas.

Da região de Mococa foram utilizados dados de duas áreas. A primeira, no Polo Regional Nordeste Paulista da APTA (Agência Paulista de Tecnologia dos Agronegócios), a $21^{\circ} 28^{\prime} \mathrm{S}$ de latitude, $47^{\circ} 01^{\prime} \mathrm{W}$ de longitude e $665 \mathrm{~m}$ de altitude, os cafeeiros foram plantados na década de 1970, em uma área de 0,76 ha de Latossolo Vermelho Distrófico, com espaçamento médio de $3,5 \times 2,0 \mathrm{~m}$ (GAllo, 1995). A segunda área, na Fazenda Serra, a $21^{\circ} 25^{\prime} \mathrm{S}, 46^{\circ} 52^{\prime} \mathrm{W}$ e $827 \mathrm{~m}$ de altitude, onde os cafeeiros foram plantados entre 1970 a 1986, em uma área de 14,2 ha, com espaçamento médio de 3,8 8 2,5 m (FAHL et al., 2001).
Da região de Campinas, foram utilizados dados de experimentos e observações desenvolvidos no Centro Experimental de Campinas do IAC, a $22^{\circ} 54^{\prime} \mathrm{S}$ de latitude, $47^{\circ} 05^{\prime} \mathrm{W}$ de longitude e $674 \mathrm{~m}$ de altitude, e na Fazenda Monte D'Este, localizada a $22^{\circ} 50^{\prime} \mathrm{S}, 46^{\circ} 55^{\prime} \mathrm{W}$ e $650 \mathrm{~m}$ de altitude. Os cafeeiros foram plantados entre 1970 e 1985, em Latossolo Vermelho Eutroférrico, com espaçamento médio de 3,3 $\mathrm{m}$ entre linhas e 2,0 m entre plantas.

Para ambas as regiões, consideraram-se datas do início da florada plena, quando as gemas florais maduras transformaram-se em flores com um total de 26 cíclos. As adubações, tratos culturais e tratamentos fitossanitários foram os usualmente recomendados para a cultura comercial do café, sem aplicação de irrigação.

\subsection{Dados meteorológicos}

Dados históricos diários de precipitação pluvial $(\mathrm{mm})$ e temperaturas máximas e mínimas do ar $\left(\mathrm{C}^{\circ}\right)$ foram obtidos nos arquivos do Centro de Pesquisa e Desenvolvimento em Ecofisologia e Biofísica do IAC, oriundos dos postos meteorológicos existentes nas áreas experimentais de Campinas e Mococa, os quais foram consistidos.

\subsection{Cálculo dos balanços hídricos}

O cálculo do balanço hídrico seqüencial, para estimar a disponibilidade hídrica do solo, foi realizado pelo programa proposto por Rolim et al. (1998), feito em planilhas no ambiente EXCEL ${ }^{\mathrm{TM}}$, baseado no método de Thornthwaite e Mather (1955), em escala decendial, considerando a capacidade máxima de água disponível (CAD) igual a $100 \mathrm{~mm}$, que atende à grande maioria dos solos das áreas cafeeiras do Estado de São Paulo (Camargo e Pereira, 1994).

Através dos balanços hídricos são gerados valores decendiais da demanda atmosférica, representada pela evapotranspiração potencial (ETp), que foi estimada pelo método de ThornthWAIte (1948).

Os graus-dia acumulados foram determinados pela seguinte equação:

$$
\mathrm{GD}=\sum(\mathrm{Tm}-\mathrm{TB})
$$

Em que: Tm é a temperatura média do ar $\left({ }^{\circ} \mathrm{C}\right)$ no decêndio e TB é a temperatura-base inferior, igual a $10{ }^{\circ} \mathrm{C}$ para o cafeeiro, de acordo com CAMARGo e Pereira (1994). 


\subsection{Modelo Agrometeorológico}

O componente fenológico do modelo agrometeorológico proposto por CAMARGO et al. (2003) visa estimar a época de início da "plena floração" do cafeeiro arábica, válido para as condições tropicais brasileiras. GouveIa (1984) verificou que, nas condições de Campinas, todas as gemas florais estão induzidas depois de março, e a abertura das flores ocorre cerca de 10 dias após as chuvas. CAMARGo e CAMARGo (2001) observaram que as gemas florais completam a maturação e entram em dormência, ficando prontas para a antese plena, quando o somatório da evapotranspiração potencial (ETp), a partir do primeiro decêndio de abril, atinge cerca de $350 \mathrm{~mm}$. A quantidade mínima de chuva necessária para que as gemas maduras sejam induzidas à antese, após a acumulação de $350 \mathrm{~mm}$ de ETp, é de no mínimo $10 \mathrm{~mm}$.

Neste trabalho, utilizou-se o somatório acumulado de ETp, a partir de abril para fazer a previsão da época (decêndio) em que as gemas florais do cafeeiro atingiam a maturidade fisiológica. Para isso, consideraram-se valores de ETp acumulados iguais a $330,335,340,345,350,355,360$ e $365 \mathrm{~mm}$. Foram calculados, também, os valores correspondentes de GD. Após essas acumulações de ETp ou de GD, consideraram-se quantidades mínimas de chuva, necessárias para induzir a antese, de 1 a $10 \mathrm{~mm}$, estimando a época de ocorrência da florada plena.

\subsection{Análise estatística}

Para a avaliação das estimativas das floradas plenas, foram utilizadas análises de regressão linear. Ao correlacionar valores estimados com os observados, consideraram-se indicadores estatísticos como o coeficiente de determinação $\left(R^{2}\right)$, o índice de concordância " $\mathrm{d}$ " proposto por Willmot et al. (1985) e o índice de confiança " $c$ " proposto por CAMARGo e SentelHas (1997).

Para analisar as interações entre as variáveis dependentes (início do florescimento) e independentes (chuva e ETp), e verificar a reposta ótima dentre as diversas combinações de fatores, utilizaram-se gráficos de superfície de resposta, feitos através do programa STATISTICA 6.0.

\section{RESULTADOS E DISCUSSÃO}

3.1 Relação entre valores acumulados de ETp e de graus-dia

Ao relacionar os valores acumulados de ETp, calculados pelos balanços hídricos, com os valores correspondentes de graus-dia, calculados considerando-se valores de temperaturas médias decendiais, das regiões de Campinas e Mococa, obteve-se uma equação polinomial de $4 .^{\circ}$ grau, resultando em um $R^{2}$ de 0, 997 (Figura 1). Por esses resultados, observa-se que essas duas variáveis têm uma alta correlação, sugerindo que ambas podem ser usadas para estimar a época de maturação das gemas florais.

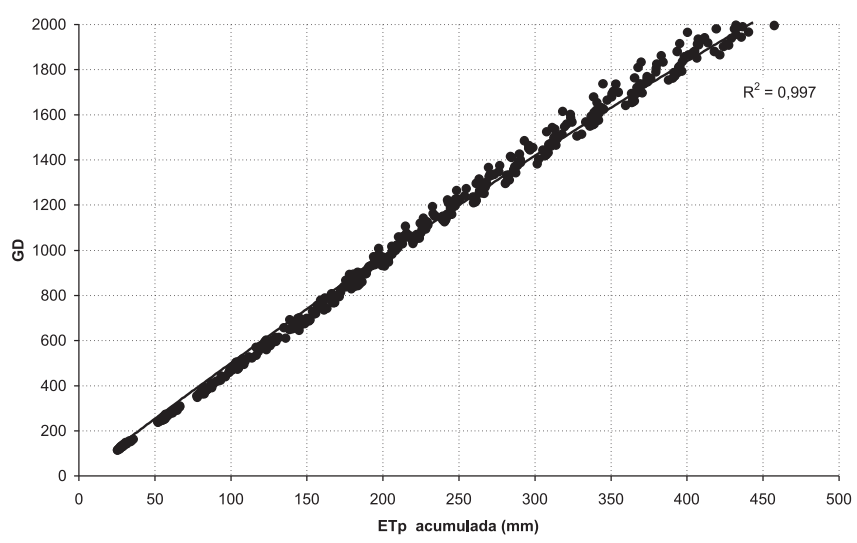

Figura 1. Relação entre valores acumulados de ETp (mm) e Graus-dia $\left({ }^{\circ} \mathrm{C}\right)$, para as regiões de Campinas e Mococa (SP), de 1993 a 2005.

Na tabela 1, são apresentados os valores correspondentes das duas variáveis estimados pela seguinte equação polinomial de $4^{\circ}$ grau gerada pela análise de regressão:

$$
Y=1,186 \times 10^{-8} X^{4}-1,781 \times 10^{-5} X^{3}+0,007
$$
$X^{2}+3,903 X$

Em que: $\mathrm{Y}$ é graus-dia $\left({ }^{\circ} \mathrm{C}\right)$ e $\mathrm{X}$ o valor acumulado de $\operatorname{ETp}(\mathrm{mm})$.

Tabela 1. Valores de graus-dia estimados pela análise de regressão em função de valores de ETp acumulados

\begin{tabular}{lc}
\hline ETp acumulados & Graus-dia \\
\hline $\mathrm{mm}$ & ${ }^{\circ} \mathrm{C}$ \\
330 & 1557 \\
335 & 1579 \\
340 & 1601 \\
345 & 1623 \\
350 & 1644 \\
355 & 1666 \\
360 & 1687 \\
365 & 1709 \\
\hline
\end{tabular}


3.2 Análise das interações de valores de ETp e de GD com diferentes valores de precipitação pluvial

\section{Campinas}

Com o intuito de se estimar com maior consistência a época de ocorrência das floradas plenas do cafeeiro arábica para a região de Campinas, utilizaram-se diferentes valores de ETp (330 a $365 \mathrm{~mm}$ ) e de chuva (1 a $10 \mathrm{~mm}$ ). Na figura 2 , são apresentados os erros de estimativa obtidos, em número de decêndios.

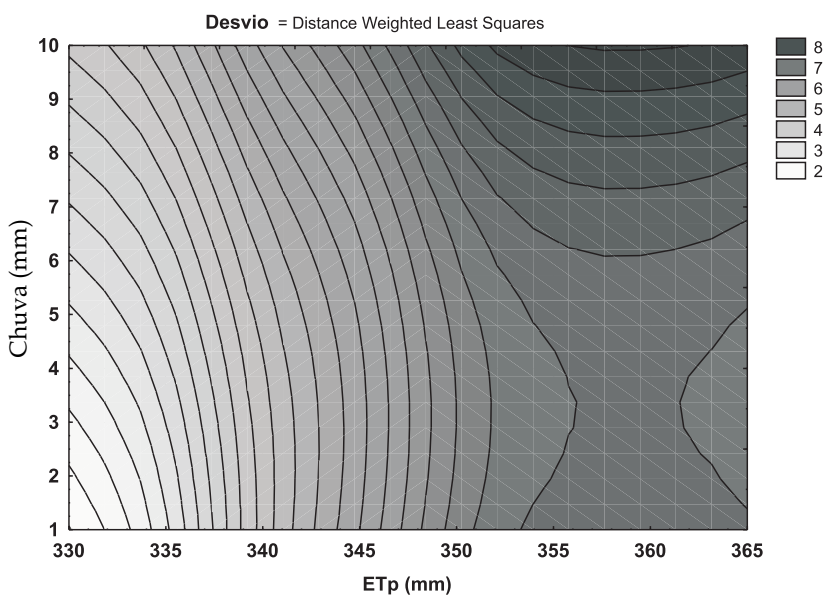

Figura 2. Total de erros de estimativa (desvios em decêndios) da florada plena do cafeeiro arábica, em função das combinações de diferentes valores de ETp acumulados ( $\mathrm{mm})$ e deprecipitação pluvial $(\mathrm{mm})$, para a região de Campinas (SP), de 1993 a 2005.

Observa-se que quanto maior o valor de ETp (340 a $365 \mathrm{~mm}$ ), maior é o total de erros (área escura), não variando muito em relação ao aumento da precipitação pluvial, apresentando totais de erros de até oito decêndios. Já a área mais clara representa os melhores resultados, com os menores valores de total de erros entre 330 e 335 mm e quantidade mínima de chuva de 1 a $3 \mathrm{~mm}$, apresentando erros de estimativa de até 2 decêndios em relação à florada real (Figura 2).

Ao se considerar valores de GD equivalentes aos valores de ETp acumulados a partir de abril (Tabela 1), observa-se comportamento semelhante, ou seja, os erros de estimativa foram maiores à medida que se aumentou o valor acumulado de GD, comprovando a alta relação entre essas duas variáveis (Figura 3). Observando-se o valor de GD acumulado de $1.644{ }^{\circ} \mathrm{C}$, equivalente a $350 \mathrm{~mm}$ de ETp, sugerido por CAMARGO e CAMARGO (2001) como o necessário para que o botão floral atingisse a maturidade e um mínimo de $10 \mathrm{~mm}$ de chuva para induzir à antese, ocorreram erros significativos, com um total de oito erros de estimativa (desvios em decêndios), conforme a figura
3. O melhor resultado foi verificado para o valor de GD igual a $1.557^{\circ} \mathrm{C}$ e chuva mínima de 1 a $3 \mathrm{~mm}$ (Figura 3).

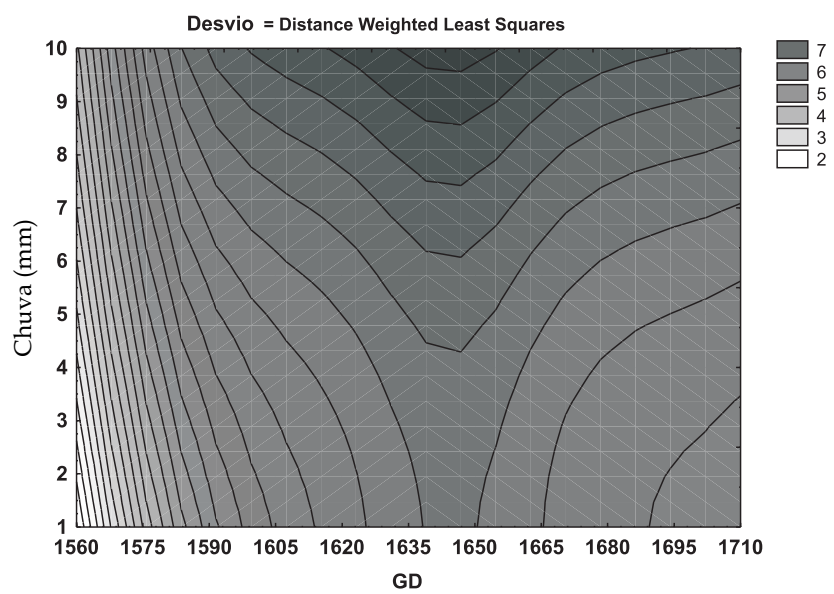

Figura 3. Total de erros de estimativa (desvios em decêndios) da florada plena do cafeeiro arábica, em função das combinações de diferentes valores de grausdia (GD) acumulados e de precipitação pluvial (mm), para a região de Campinas (SP), de 1993 a 2005.

Entretanto, para Campinas, foram observados erros de até três decêndios em relação à florada real, quando se considerou GD. Esse fato ocorreu porque a ETp considera o acúmulo térmico e o comprimento do dia, enquanto os graus-dia consideram apenas o acúmulo da média das temperaturas máxima e mínima do ar, podendo ser menos confiável, apresentado mais falhas na estimativa da época de maturação das gemas florais.

\section{Mococa}

Para estimar a época de ocorrência das floradas plenas do cafeeiro arábica na região de Mococa, consideraram-se os mesmos valores de ETp e de chuva de Campinas, obtendo-se erros de estimava, em número de decêndios, que estão apresentados na figura 4.

Observa-se que os melhores resultados (área mais clara) são para as interações de menores valores de ETp (330 e $340 \mathrm{~mm}$ ) e maiores quantidades de chuva mínima (6 a $8 \mathrm{~mm}$ ), para os quais as floradas estimadas foram bem próximas das floradas reais, com totais de erros de dois decêndios. Observou-se, também, melhora da estimativa para a combinação de ETp em torno de $360 \mathrm{~mm}$ e precipitação pluvial entre 5 e $7 \mathrm{~mm}$ (Figura 4). Ao contrário de Campinas, que indica uma quantidade de chuva de 1 a $3 \mathrm{~mm}$ (Figura 2) para quebrar a dormência das gemas, a região de Mococa necessita de quantidade maior de chuva. 


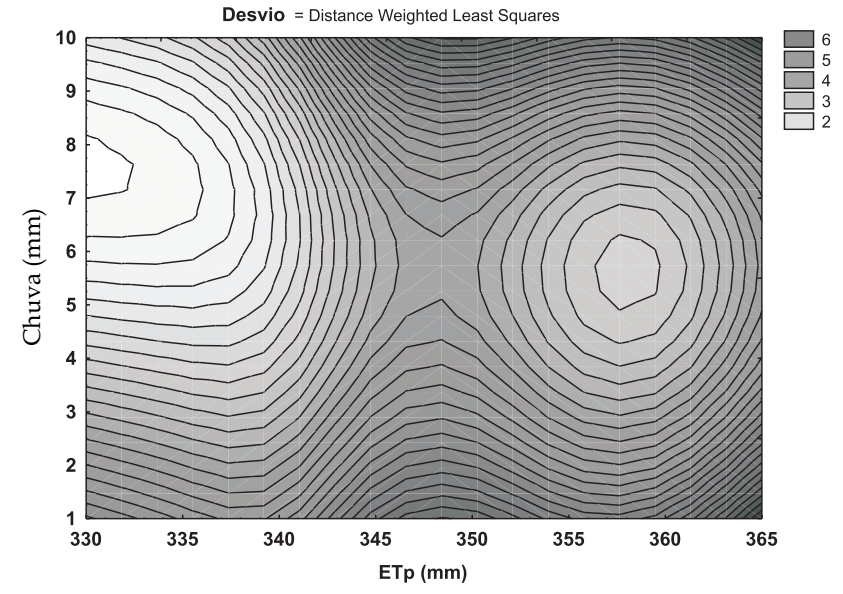

Figura 4. Total de erros de estimativa (desvios em decêndios) da florada plena do cafeeiro arábica, em função das combinações de diferentes valores de ETp acumulados $(\mathrm{mm})$ e de precipitação pluvial $(\mathrm{mm})$, para a região de Mococa (SP), de 1993 a 2005.

Quando se consideram valores de GD para estimar a florada, obtiveram-se resultados semelhantes aos de ETp. Os totais de erros menores foram para 1557, 1579 e 1601 graus-dia, com chuvas entre 6 e $8 \mathrm{~mm}$, sendo iguais a dois decêndios, conforme a figura 5 .

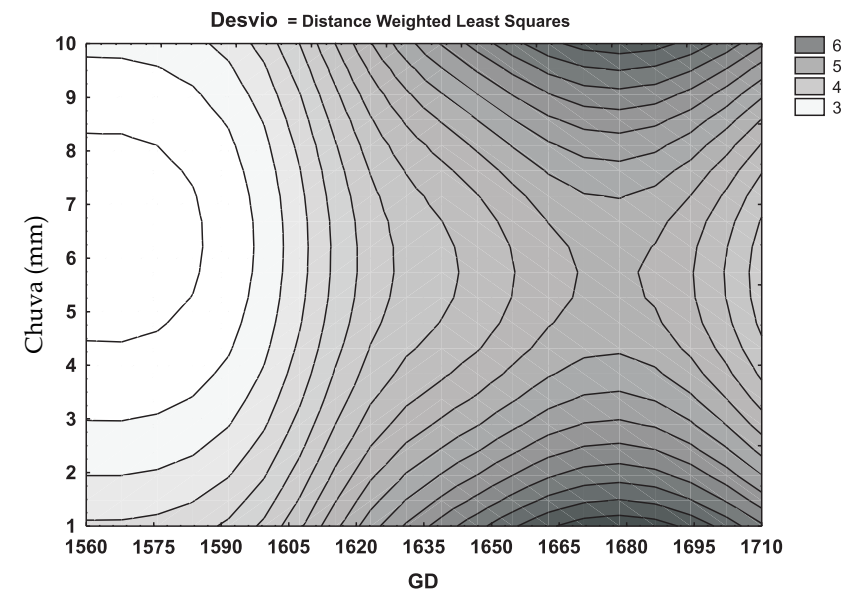

Figura 5. Total de erros de estimativa (desvios em decêndios) da florada plena do cafeeiro arábica, em função das combinações de diferentes valores de grausdia (GD) acumulados e de precipitação pluvial (mm), para a região de Mococa (SP), de 1993 a 2005.

\subsection{Análise conjunta dos resultados estatísticos para Campinas e Mococa}

Ao analisar todas as combinações de valores de ETp acumulados e de precipitação pluvial, tanto para a região de Campinas como para a de Mococa, selecionaram-se aquelas com os melhores índices estatísticos, e os resultados estão apresentados na tabela 2. Verifica-se que, para Campinas, os maiores índices estatísticos foram obtidos para combinações que consideraram valores acumulados de ETp entre 330 e $335 \mathrm{~mm}$, e chuvas variando de 1 a $10 \mathrm{~mm}$. Os valores do índice " $d$ " foram elevados, entre 0,87 e 0,90 , indicando boa exatidão do modelo em prever o início da florada plena do cafeeiro para esta região. Os valores de $\mathrm{R}^{2}$ variaram de 0,66 a 0,69 , indicando uma pequena dispersão dos dados obtidos em relação à média. Levando-se em consideração apenas o índice "c", observou-se que não ocorreu variação estatística entre essas combinações, sendo igual a 0,60 que, segundo Camargo e Sentelhas (1997), não indica bom desempenho do modelo.

Para Mococa, observaram-se melhores resultados para as combinações de valores de ETp acumulados entre 330 e $340 \mathrm{~mm}$, e de chuvas entre 6 e $10 \mathrm{~mm}$. Os valores do índice "c" de confiança foram mais elevados para esta região do que para Campinas, sendo igual a 0,70, indicando bom desempenho do modelo (CAmargo e Sentelhas, 1997). Os índices "d" e $\mathrm{R}^{2}$ também foram mais elevados, 0, 93 e 0,75 respectivamente, revelando boa precisão e exatidão do desempenho do modelo em estimar o início da florada plena (Tabela 2).

Tabela 2. Resultados estatísticos da análise da estimativa da florada plena para Campinas e Mococa, SP, em função das combinações de valores de ETp acumulados (mm), a partir de abril, e de precipitação pluvial (mm)

\begin{tabular}{|c|c|c|c|c|c|}
\hline Região & ETp & Precipitação & $\mathrm{d}$ & $\mathrm{R}^{2}$ & c \\
\hline & & $\mathrm{mm}$ & & & \\
\hline \multirow{9}{*}{ Campinas } & 330 & 3 & 0,90 & 0,66 & 0,60 \\
\hline & 335 & 1 & 0,90 & 0,66 & 0,60 \\
\hline & 335 & 2 & 0,90 & 0,66 & 0,60 \\
\hline & 335 & 3 & 0,90 & 0,66 & 0,60 \\
\hline & 330 & 8 & 0,87 & 0,69 & 0,60 \\
\hline & 330 & 9 & 0,87 & 0,69 & 0,60 \\
\hline & 330 & 10 & 0,87 & 0,69 & 0,60 \\
\hline & 335 & 8 & 0,87 & 0,69 & 0,60 \\
\hline & 335 & 9 & 0,87 & 0,69 & 0,60 \\
\hline & 335 & 10 & 0,87 & 0,69 & 0,60 \\
\hline \multirow{10}{*}{ Mococa } & 340 & 10 & 0,92 & 0,72 & 0,66 \\
\hline & 330 & 6 & 0,93 & 0,75 & 0,70 \\
\hline & 330 & 7 & 0,93 & 0,75 & 0,70 \\
\hline & 330 & 8 & 0,93 & 0,75 & 0,70 \\
\hline & 335 & 6 & 0,93 & 0,75 & 0,70 \\
\hline & 335 & 7 & 0,93 & 0,75 & 0,70 \\
\hline & 335 & 8 & 0,93 & 0,75 & 0,70 \\
\hline & 340 & 6 & 0,93 & 0,75 & 0,70 \\
\hline & 340 & 7 & 0,93 & 0,75 & 0,70 \\
\hline & 340 & 8 & 0,93 & 0,75 & 0,70 \\
\hline Média & 335 & 7 & 0,91 & 0,71 & 0,65 \\
\hline
\end{tabular}

d: índice "d" de concordância de Willmott; $R^{2}$ : coeficiente de determinação; c: índice "c" de confiança 
Considerando-se a média dos resultados estatísticos de Campinas e Mococa, foi observado que a melhor parametrização para o modelo seria com valores de $335 \mathrm{~mm}$ de ETp acumulado, a partir de abril, e ocorrência de chuva mínima de $7 \mathrm{~mm}$ como a melhor interação do modelo fenológico para se estimar a época de ocorrência da florada plena do cafeeiro, para as condições tropicais do Estado de São Paulo (Tabela 2). Esses valores diferem dos sugeridos por CAMARGO e CAMARGO (2001), que consideraram o valor de ETp em torno de $350 \mathrm{~mm}$ e chuva mínima de $10 \mathrm{~mm}$, para a indução da antese. $\mathrm{O}$ valor de $7 \mathrm{~mm}$ determinado está de acordo com Damatta e Rena (2002) e Damatta e Ramalho (2006) que constataram ser suficientes de 5 a $10 \mathrm{~mm}$ de chuva para quebrar a dormência das gemas florais.

O modelo agrometeorológico parametrizado pode ser incorporado a modelos agrometeorológicos de monitoramento e de estimativa de quebra de produtividade, que necessitam desta importante informação fenológica.

\section{CONCLUSÕES}

1. A evapotranspiração potencial acumulada a partir de abril e a precipitação pluvial, que ocorre após as gemas florais atingirem a maturação, são variáveis meteorológicas importantes para serem utilizadas na estimativa da época da florada plena do cafeeiro arábica, nas condições tropicais do Estado de São Paulo.

2. O modelo agrometeorológico parametrizado, que considera o valor de ETp acumulado a partir de abril igual a $335 \mathrm{~mm}$, para as gemas florais atingirem a maturação, e a ocorrência de um mínimo de $7 \mathrm{~mm}$ de chuva, para quebrar a dormência das gemas maduras, apresentou boa capacidade revelando a época da plena floração do cafeeiro arábica, com erros de estimativa inferiores ao modelo original de CAMARgo e CAMARgo (2001).

3. O modelo agrometeorológico, quando considera valores de graus-dia para estimar a época da florada plena, foi de desempenho inferior, comparado com os valores de ETp.

\section{AGRADECIMENTOS}

À Coordenadoria de Aperfeiçoamento de Ensino Superior (CAPES) pela concessão da bolsa de estudo e à Empresa Brasileira de Pesquisa Agropecuária (EMBRAPA/PNP\&D/CAFÉ) pelo financiamento do projeto.

\section{REFERÊNCIAS}

ARNOLD, C.Y. The determination and significance of the base temperature in a linear heat unit system. Proceedings of American Society Horticultural Science, Virginia, v.74, n.4, p.430-445, 1959.

CAMARGO, A. P. Contribuição para a determinação da evapotranspiração potencial no Estado de São Paulo. Bragantia, Campinas, v.21, n.12, p.163-203, 1962.

CAMARGO, A.P.; CAMARGO, M.B.P. Uma revisão analítica da evapotranspiração potencial. Artigo de Revisão. Bragantia, Campinas, v.59, n.2, p.125-137, 2000.

CAMARGO, A.P.; CAMARGO, M.B.P. Definição e esquematização das fases fenológicas do cafeeiro arábica nas condições tropicais do Brasil. Bragantia, Campinas, v.60, n.1, p.65-68, 2001.

CAMARGO, A.P.; PEREIRA, A.R. Agrometeorology of the coffe crop. Geneve: World Meteorological Organization, 1994. 96p. (Agricultural Meteorology CaM report, 58)

CAMARGO, A.P.; SENTELHAS, P.C. Avaliação do desempenho de diferentes métodos de estimativa da evapotranspiração potencial no Estado de São Paulo, Brasil. Revista Brasileira de Agrometeorologia, Santa Maria, v. 5, n. 1, p.89-97, 1997.

CAMARGO, M.B.P.; SANTOS, M.A.; PEDRO JUNIOR, M.J.; FAHL, J.I.; BRUNINI, O.; MEIRELES, E.J.L.; BARDIN, L. Modelo agrometeorológico de monitoramento e de estimativa de quebra de produtividade como subsidio à previsão de safra de café (Coffea arabica L.): resultados preliminares. In: SIMPÓSIO DE PESQUISA DOS CAFÉS DO BRASIL, 3., 2003, Porto Seguro. Anais... Porto Seguro: Consórcio Brasileiro de Pesquisa e Desenvolvimento do Café, 2003. p.75-76.

CARVALHO, L.G.; SEDIYAMA, G.C.; CECON, P.R.; RAMOS ALVES, H.M. Avaliação de um modelo agrometeorológico para previsão de produtividade de café em três localidades da região sul do Estado de Minas Gerais. Revista Brasileira de Agrometeorologia, Santa Maria, v.11, n.2, p.343-352, 2003.

DAMATTA, F.M.; RENA, A.B. Relações hídricas no cafeeiro. In: SIMPÓSIO DE PESQUISA DOS CAFÉS DO BRASIL, 1., 2000, Poços de Caldas. Anais... Brasília, DF: Embrapa Café, 2002. p.9-44.

DAMATTA, F.M.; RAMALHO, J.D.C. Impacts of drought and temperature stress on coffee physiology and production: a review. Brazilian Journal of Plant Physiology, Campinas, v.18, n.1, p.55-81, 2006

FAHL, J.I.; CAMARGO, M.B.P; ALFONSI, E.L.; SANTOS, M.A. Efeito das condições climáticas sobre a bienalidade da produtividade do café arábica na região de Mococa, SP. In: CONGRESSO BRASILEIRO DE AGROMETEOROLOGIA, 12., 2001, Fortaleza. Anais... Fortaleza: Sociedade Brasileira de Agrometeorologia, 2001. p.155-156. 
GALLO, P.B. Comportamento de progênie de café Mundo Novo (Coffea arabica L.) em Mococa, SP. 1995. 53f. Dissertação (Mestrado em Agronomia) - Escola Superior de Agricultura "Luiz de Queiroz", USP, Piracicaba.

GOUVEIA, N.M. Estudo da diferenciação e crescimento de gemas florais de Coffea arabica L.: observações sobre a antese e maturação dos frutos. 1984. 237f. Dissertação (Mestrado em Biologia) - Instituto de Biologia, UNICAMP, Campinas.

PEREIRA, A.R.; ANGELOCCI, L.R.; SENTELHAS, P.C. Agrometeorologia: Fundamentos e Aplicações Práticas. Guaíba: Agropecuárias, 2002. 465p.

ROLIM, G.S.; SENTELHAS, P.C.; BARBIERI, V. Planilhas no ambiente EXCEL ${ }^{\mathrm{TM}}$ para os cálculos de balanços hídricos: normal, seqüencial, de cultura e de produtividade real e potencial. Revista Brasileira de Agrometeorologia, Santa Maria, v. 6, n. 1, p.133-137, 1998.

SANTOS, M.A.; CAMARGO, M.B.P. Parametrização de modelo agrometeorológico de estimativa de produtividade do cafeeiro nas condições do Estado de São Paulo. Bragantia, Campinas, v.65, n.1, p.173-183, 2006.
SILVA, E.A.; MAZZAFERA, P.; BRUNINI, O.; SAKAI, E.; ARRUDA, F.B.; MATTOSO, L.H.C.; CARVALHO, C.R.L.; PIRES, R.C.M. The influence of water managemet and environmental conditions on the chemical composition and beverage quality of coffee beans. Brazilian Journal of Plant Physiology, Campinas, v.17, n.2, p.229-238, 2005.

THORNTHWAITE, C.W. An approach toward a rational classification of climate. Geography Review, v 38, p. 55-94, 1948.

THORNTHWAITE, C.W.; MATHER, J.R. The water balance. Centerton, NJ: Drexel Institute of Technology - Laboratory of Climatology, 1955. 104p. (Publications in Climatology, v. 8, n.1)

WILMOTT, C.J., ACKLESON, S.G.; DAVIS, J.J., et al. Statistics for the evaluation and comparison of models. Journal of Geography Research, v. 90, n. 5, p. 8995-9005, 1985. 